\title{
Determination Of Menopausal Symptoms, Sleep Levels, And Quality Of Life Of Women Who Applied To Menopause School And Self-Examination Of Breasts And Vulva
}

\author{
Yeliz Kaya ${ }^{1}$, Dilek Sayik ${ }^{2}$, and Muzaffer Bilgin ${ }^{3}$ \\ 1, Eskişehir Osmangazi University Faculty of Health Sciences, \\ ${ }^{2}$ Eskisehir City Hospital \\ ${ }^{3}$ Eskişehir Osmangazi University Faculty of Medicine
}

August 2, 2020

\begin{abstract}
Aim: The aim of this study was to determine menopausal symptoms, sleep levels, quality of life of women in the premenopausal, menopausal, and postmenopausal period, to increase their knowledge level with training to be provided, to reduce their menopausal symptoms, to improve quality of life and sleep quality, and to enable self-examination of breasts and vulva with training provided. Method: The research was conducted in a public hospital in Eskişehir. The study had a quasi-experimental design. The sample of the research consisted of 36 women aged between 40-65 years. These women were asked to complete the Sociodemographic Characteristics Determination Form, Menopause Rating Scale, Pittsburgh Sleep Quality Index, and Quality of Life Scale (SF-36) when they applied to menopause school. After the forms were completed, the participants were given training. Following training, the scales were re-completed and then women were enabled to perform self-examination of breasts (SEB) and self-examination of the vulva (SEV). The IBM SPSS Statistics 21.0 was used for the analysis. Results: The mean age of the women was $50.66 \pm 4.45$ and that the mean menopause age was $47.60 \pm 3.45$. The most frequently described symptom was fatigue (91.7\%). It was seen that after the training, the MRS score of the women decreased from $16.83 \pm 8.87$ to $13.66 \pm 8.36$; the PSQI score decreased from $14.34 \pm 2.64$ to $13.81 \pm 2.55$; the mean Quality of Life (SF-36) scale score increased from $48.74 \pm 19.13$ to $54.92 \pm 17.40$. As a result of SEB and SEV performed by the women after the training, it was determined that $5.6 \%$ of the women had a breast deformity, that $8.3 \%$ had a palpable mass in the breast and that $13.9 \%$ detected a vaginal discharge in the vulva examination $(\mathrm{p}<0.05)$. Conclusion: It is easier to overcome this period with specific comprehensive training and women are enabled to cope with symptoms more effectively.
\end{abstract}

\section{Hosted file}

3. ANA MET\selectlanguage\{polish\}İ $\backslash$ selectlanguage\{english\}N.DOCX available at https: //authorea.com/users/348108/articles/473602-determination-of-menopausal-symptomssleep-levels-and-quality-of-life-of-women-who-applied-to-menopause-school-and-selfexamination-of-breasts-and-vulva

\section{Hosted file}

4-TABLOLAR .DOCX available at https ://authorea.com/users/348108/articles/473602-determinationof-menopausal-symptoms-sleep-levels-and-quality-of-life-of-women-who-applied-tomenopause-school-and-self-examination-of-breasts-and-vulva 